\title{
How the Sustainable Development Goals risk undermining efforts to address environmental and social issues in the small-scale mining sector
}

\begin{abstract}
Artisanal and small-scale mining (ASM) provides a source of livelihood for millions of mostly poor people across the globe. At the same time, however, the sector is predominantly informal and associated with a range of persistent social and environmental challenges, including chronic poverty, deforestation, land degradation, mercury pollution and river siltation. The ASM sector is connected to all the United Nations' Sustainable Development Goals (SDGs) in ways which both support and undermine their achievement. Attention, therefore, is growing on how the sector can shape, and be shaped by, the pursuit of the SDGs. This paper aims to articulate the linkages and interactions between ASM and the SDGs to inform ongoing debates about how to address the sector's social and environmental impacts. The review engages with three key, and closely related, issues that are central to determining the potential for synergies to emerge between ASM and the SDGs. These are: 1 ) the large-scale bias in mining policy; 2) debates around formalisation; and 3) knowledge. It is argued that the SDGs, their 169 targets and 232 indicators, and the state and corporate driven processes behind their development serve to exacerbate the large-scale bias; promote an approach to formalisation that risks marginalising the poorest and entrenching inequality, and privilege techno-scientific knowledge at the expense of studies which examine the governance systems that actually dictate who, where, how and why people engage with ASM, knowledge that is essential for effective policy design. The review concludes that the prospects for the SDGs contributing positively to efforts to address environmental and social issues in ASM are poor. Worryingly, similar arguments apply across a range of important sectors, such as forestry and agriculture, where informality and poverty are also widespread. Raising the prospects for the SDGs requires focussing less on measuring whether or not particular indicators are met but rather on understanding what such goal-setting governance systems actually do with respect to the lives of their intended beneficiaries and the environments they inhabit. Such an understanding can inform strategies to resist the more pernicious effects of ostensibly unobjectionable global sustainability agendas.
\end{abstract}

Keywords: Artisanal and small-scale mining (ASM); Sustainable Development Goals (SDGs); Large-scale bias; Formalisation; Knowledge politics 


\section{Introduction}

Mining is linked to all the Sustainable Development Goals (SDGs) in ways which both support and undermine their achievement. Connections between artisanal and small-scale mining (ASM) - the low-tech, labour-intensive extraction of minerals - and the SDGs are of particular concern, however, given the sector's neglected role on the development agenda, despite its link to poverty and sizable environmental impact (e.g. Ghose, 2003; Hilson, 2019; Hilson and McQuilken, 2014; Hilson and Pardie, 2006; Hirons, 2011; Hook, 2019; TarrasWahlberg et al. 2000; Telmer and Veiga, 2009). This paper reviews the connections between the SDGs and ASM, and reflects on the prospects for synergies and antagonisms. The article focusses on environmental issues, but the core arguments are relevant across the spectrum of challenges associated with the sector. The analysis demonstrates that while there are numerous links between the broader SDGs and ASM, the constellation of state and corporate interests behind the configuration of targets and indicators risks further marginalising the sector and undermining efforts to address associated environmental issues. Addressing these concerns requires leveraging the SDGs to provide a much more comprehensive understanding of ASM, reverse the ongoing marginalisation of the sector in development policy, and engage with the challenges of formalising of its activities.

The ASM sector directly employs an estimated 40 million people and indirectly supports the livelihoods of an additional 150 million people across 80 countries in the Global South (IGF, 2017). They mine a number of minerals, including, gold, diamonds, sapphire and rare earth minerals, using a range of rudimentary techniques. Between 70 and $80 \%$ of the sector's activities are informal (IGF, 2017). The ease with which labour can enter the sector, and dearth of alternative income-earning opportunities in many counties, particularly in rural areas, has led to the sector becoming a critical source of employment for the poorest groups in society (Yakovleva, 2007; Banchirigah and Hilson, 2009). The ASM sector features a heterogeneous group of actors. This diversity underlies many of the ongoing debates about the sector, including the social and environmental challenges the sector faces and how to address them (see e.g. Verbrugge, 2015). However, there is a broad consensus that the bulk of ASM's labour force is driven into the sector by poverty and that it generally provides a meaningful livelihood, whether seasonally or more permanently (Bryceson and Geenen 2016; Hilson and Pardie, 2006; Hilson, 2016; IGF, 2017; Zvarivadza, 2018). These broad social benefits are often pitted against the environmentally damaging practices associated with the sector, including, land degradation and deforestation, mercury pollution and river siltation. As such, the sector epitomises the sustainability challenge: economic activities that have fostered economic and social development are simultaneously associated with environmental degradation (as well as a range of deleterious social issues).

Understanding the persistent growth of ASM and associated environmental impacts requires couching discussions in analyses of wider social and political landscapes. This is essential to avoiding the risk that a narrow focus on the detrimental environmental impacts of ASM embeds characterisations of the sector as a scourge on society and implicitly supports associated calls for the informal sector to be eradicated entirely (e.g. Bansah, 2019; Hilson, 2017). Such calls are not merely rooted in environmental concerns; they are 
also deeply intertwined with the wider political economy of the sector and questions regarding the distribution of benefits from mining. In order to situate and frame the analysis appropriately, this paper draws on three critical and related issues seen here as central to understanding the ASM sector. The first is the idea of a 'large-scale bias' (Hilson, 2019), which has emerged as an explanation for the neglect of ASM in regulatory and legislative frameworks and the proliferation of the sector's informality. The second is formalisation efforts aimed at integrating ASM into a legal framework governed by the state - which has arisen as a core policy response to address the challenges of the sector (Hilson and Maconachie, 2017; Hilson, 2019). Formalisation efforts to date have largely failed to address their stated aim of addressing, inter alia, the environmental impacts of ASM. The third concerns diagnoses of this failure, largely attributable to poor knowledge of the sector, particularly its governance arrangements which in places are rather modest (Jonsson and Fold, 2009). Even in countries and contexts where there is a relatively sound understanding of the sector's dynamics, these details have failed to inform the design of formalisation processes. These three elements - the large-scale bias, formalisation and knowledge of ASM's dynamics - are central to understanding the future of the sector, and key to bolstering efforts aimed at addressing its social and environmental challenges.

Efforts to address such challenges are increasingly being organised around the Sustainable Development Goals (SDGs) which are at the heart of the United Nations' 2030 Agenda for Sustainable Development. This agenda, which was adopted by all member states in 2015, aims to provide a 'shared blueprint for peace and prosperity for people and the planet, now and into the future' (United Nations, 2020). The 17 goals - and the 169 targets and 232 indicators - will guide development investment in the coming decade (Griggs et al. 2013; Hák et al. 2016). The SDGs represent a form of 'governance by goal -setting' (Bierman et al. 2017), the efficacy of which is brought into question by the non-binding character of the goals, the extensive leeway states enjoy in setting priorities and the reliance on existing institutional arrangements with a debatable-record of delivering on global development goals (Kumi et al. 2014; Biermann, 2017; Liverman, 2018). The effects of the SDGs are contingent on how states and other interested parties such as private companies, which played a key role in the development of the goals (Scheyvens et al. 2016), translate and attempt to address specific indicators and targets through legal, policy and institutional reform in and across particular sectors (Bierman et al. 2017; Fukuda-Parr and McNeill, 2019; Kumi, 2014). As a result, clear lines of sight between the SDGs and their impacts are unlikely to emerge. Rather, the SDGs are likely, in the words of Li (2005), to have a range of 'messy, contradictory and refractory effects' (p. 391).

It is against this background that the paper explores how the SDGs might influence efforts to address the social and environmental impacts of the ASM sector. The paper proceeds by reviewing the literature on ASM, first by reflecting on the sector's impacts and links to the SDGs with an emphasis on environmental issues, and subsequently through engaging in contemporary debates on the large-scale bias, formalisation and knowledge of the sector. The structure of the SDGs is briefly examined to lay the foundations for analysing their likely influence on the ASM sector. 


\section{The ASM sector and the SDGs: contextualising contemporary trade-offs in policy debates}

\subsection{Contextualising and characterising ASM's environmental impacts}

The environmental impacts of ASM are often drawn on to paint the sector in a negative light, and to leverage support for efforts to 'control' its activities in ways which obfuscate wider political considerations. This includes, for example, the relative priority of small versus large-scale mining. It is therefore appropriate to situate this review of the environmental issues linked to ASM in an analysis which considers wider social issues, especially in light of the integrative ideals associated with the SDGs (Stafford-Smith, 2017). Trade-offs between potentially conflicting goals encapsulated in the SDGs are central to addressing the challenges facing the sector. Table 1 illustratively summarises across a number of goals how the ASM sector represents both an opportunity and a challenge entailing a number of potential synergies and antagonisms.

Table. 1. Illustrative connections between selected key SDGs and ASM

\begin{tabular}{|c|c|c|}
\hline \multirow{2}{*}{$\begin{array}{l}\text { Sustainable development } \\
\text { Goal }\end{array}$} & \multicolumn{2}{|c|}{ Illustrative linkages with ASM } \\
\hline & Opportunity & Challenge \\
\hline 1. No Poverty & $\begin{array}{l}\text { ASM generates income } \\
\text { among poorest and } \\
\text { contributes to poverty } \\
\text { alleviation }\end{array}$ & $\begin{array}{l}\text { ASM linked with poverty } \\
\text { traps }\end{array}$ \\
\hline 2. Zero Hunger & $\begin{array}{l}\text { Income generation supports } \\
\text { food security; mining- } \\
\text { agriculture co-investments, }\end{array}$ & $\begin{array}{l}\text { ASM negatively impacts } \\
\text { productive land }\end{array}$ \\
\hline $\begin{array}{l}\text { 3. Good Health and } \\
\text { Wellbeing }\end{array}$ & $\begin{array}{l}\text { Income can increase access } \\
\text { to health care. }\end{array}$ & $\begin{array}{l}\text { Health concerns in mining } \\
\text { communities, particularly } \\
\text { mercury poisoning. }\end{array}$ \\
\hline 4. Quality Education & $\begin{array}{l}\text { Income from ASM supports } \\
\text { children's education and } \\
\text { school attendance }\end{array}$ & $\begin{array}{l}\text { Children may miss school } \\
\text { to mine }\end{array}$ \\
\hline 5. Gender Equality & $\begin{array}{l}\text { Low barriers to entry, } \\
\text { provides employment for } \\
\text { women }\end{array}$ & $\begin{array}{l}\text { Labour dynamics in ASM } \\
\text { can deliver unequal access } \\
\text { to benefits from mining }\end{array}$ \\
\hline 6. Clean water and sanitation & $\begin{array}{l}\text { Income generated by } \\
\text { mining can be invested in } \\
\text { clean water and sanitation } \\
\text { facilities. }\end{array}$ & $\begin{array}{l}\text { Mercury pollution and river } \\
\text { siltation associated with } \\
\text { ASM. }\end{array}$ \\
\hline $\begin{array}{l}\text { 8. Decent work and } \\
\text { economic growth }\end{array}$ & $\begin{array}{l}\text { Mining can be dignified and } \\
\text { meaningful work. } \\
\text { Downstream benefits for } \\
\text { employment, particularly at } \\
\text { a local level }\end{array}$ & $\begin{array}{l}\text { Poor working conditions } \\
\text { widespread in the sector. }\end{array}$ \\
\hline
\end{tabular}




\begin{tabular}{|l|l|l|}
\hline 10. Reduced inequalities & $\begin{array}{l}\text { Potential to address } \\
\text { inequality since ASM } \\
\text { provides ky support to } \\
\text { lowest income groups with } \\
\text { few alternatives. }\end{array}$ & $\begin{array}{l}\text { Women often occupy } \\
\text { lower roles in the ASM } \\
\text { hierarchy, ASM sector } \\
\text { reflects and can perpetuate } \\
\text { wider societal inequalities. }\end{array}$ \\
\hline 13. Climate Action & $\begin{array}{l}\text { Minerals required for } \\
\text { renewable energy } \\
\text { development. }\end{array}$ & $\begin{array}{l}\text { ASM a locally-important } \\
\text { driver of deforestation. }\end{array}$ \\
\hline 14. Life below water & $\begin{array}{l}\text { Potential for enhanced } \\
\text { adoption of cleaner } \\
\text { production technologies }\end{array}$ & $\begin{array}{l}\text { Mercury leakages into } \\
\text { rivers and oceans. }\end{array}$ \\
\hline 15. Life on land & $\begin{array}{l}\text { Potential to improve } \\
\text { reclamation of ASM sites to } \\
\text { productive uses. }\end{array}$ & $\begin{array}{l}\text { Locally destructive for soil, } \\
\text { water sources and } \\
\text { vegetation. }\end{array}$ \\
\hline
\end{tabular}

The importance of social and environmental trade-offs within the context of pursuing the SDGs is sharpened by recognition of the growth of ASM in recent decades. In 1999, an estimated 13 million people were engaged in ASM globally (IGF, 2018). By 2017, more than 40 million people were believed to be directly engaged in ASM activities (ibid.). Although there are debates about the causes of this growth and the characteristics of miners themselves, in general, the sector tends to support livelihoods among poor rural people who have few viable employment alternatives (SDG 1). In spite of the damage the activity can cause to land, ASM can be considered to be synergistic with agriculture. Specifically, it is a valuable source of income, particularly during dry seasons and lean periods; there is also a considerable flow of labour between the two sectors (Maconachie, 2011; Hilson, 2016). Rather than being made up of individuals looking to 'get rich quick', ASM is largely comprised of people who are driven to sites by poverty and lack of opportunities. The literature is replete with examples of descriptions of the benefits ASM provides, including how income generated is used to ensure food security (SDG 2), to access health care (SDG 3) and to cover educational costs (SDG 4) (see Hilson and Maconachie, 2020). Although there are well-documented concerns about social ills at mine sites, including exploitative child labour, sexual exploitation, poor health and debt bondage/poverty traps, the widespread positive economic benefits, in combination with a lack of realistic alternatives, go a long way toward explaining the continued growth in the sector.

Alongside debates concerning the relative social benefits and costs of ASM sit a range of less contested environmental costs which also cut across the SDGs, especially Goals 6 and 13 through 15. The environmental impacts of ASM fit broadly into three categories: terrestrial, riparian and chemical. Each is dictated by where and how ASM occurs. Terrestrial impacts refer predominantly to deforestation and land degradation, often to the extent of precluding any alternative land-use, depending on the methods used (e.g. pit or alluvial/surface). Riparian impacts such as river siltation, route disruption and re-routing are commonly associated with ASM because deposits of minerals such as gold are often most accessible in river beds and floodplains. Chemical pollution in ASM is dominated by mercury, which is used to amalgamate gold. But technologies designed to minimise emissions, such as a 'retort' to contain and recycle mercury, have low rates of use globally. 
To date, there are no global level estimates of the spatial extent of ASM. Alluvial and surface ASM activities tend to be highly degrading, removing all plants from the site, burying topsoil and leaving a series of pits and heaps of waste material which if left un-remedied, render the land un-usable indefinitely (as well as dangerous). ${ }^{1}$ However, while the impacts on land are dramatic in specific localities, in general, ASM is not considered a significant driver of deforestation globally or in any country. Hosonouma et al. (2012) estimate that large and small-scale mining contribute about $7 \%$ of global deforestation, with agriculture remaining dominant at approximately $80 \%$.

Knowledge of the spatial extent and impacts of ASM on land varies enormously between countries. It is generally challenging to find estimates of the spatial extent of ASM in most locations. One exception, however, is Peru. Here, there has been a concerted effort to quantify the ASM activities (Asner et al. 2013; Swenson et al. 2011; Potapov et al. 2014; Scullion et al. 2014. While identifying small-scale mining sites using remote sensing technologies is challenging, Asner et al. (2013) combined high resolution satellite imagery and flight aircraft-based imaging with field surveys to illustrate how the sector's activities are a major driver of deforestation in Madre de Dios (see Asner and Tupayachi (2017) for latest estimates). Although mining at an aggregate level is a minor driver of deforestation, artisanal and small-scale activities outweigh other drivers of deforestation in particular contexts. This is especially the case when indirect effects such as the interaction between mining and urban/infrastructure development are taken into account. Furthermore, concerns are amplified when activities occur in areas high in biodiversity (e.g. Gandiwa and Gandiwa, 2012).

Deforestation, and other terrestrial impacts of ASM, depends critically on where activities take place. Riparian and chemical impacts are contingent both on where and how mining happens, but are also more spatially diffuse than terrestrial impacts. The scale of riparian disruptions increase with proximity of mining activities to rivers (Dondeyene, et al 2007). These impacts can affect the quality of drinking water, fish and other biotic life, increase flood risks and disrupt reservoir and damming systems. A recent study by Bansah et al. (2018) in Ghana showed that ASM can lead to the Water Quality Index being 500\% higher than the upper threshold for potability. These impacts are felt most acutely at mine sites, but also have significant impacts downstream. However, despite recent efforts to utilise modelling techniques to overcome the challenges associated with collecting data on these impacts (e.g. Masocha et al., 2019), they are generally poorly mapped and quantified, particularly at national and international scales.

\footnotetext{
${ }^{1}$ In theory, land at ASM sites can be reclaimed as successfully as large-scale sites. This means some degree of productivity can be returned to the land, but mostly, land cannot be restored to its original state on timescales that are meaningful for livelihoods or policy-making (i.e. sub-decadal), especially in the case of primary forest which cannot be effectively restored. There are no analyses concerning the rates of reclamation at ASM sites but it is generally thought to be rare because of the informal and unregulated nature of activities and the requirements for significant investment (Hirons, 2011; Hirons, 2013).
} 
The emphasis of research on the environmental impacts of ASM has been on chemical pollution, particularly mercury. ${ }^{2}$ Telmer and Veiga (2009) estimate that artisanal and smallscale gold mining is the single largest source of mercury pollution, accounting for one third of global (mercury) emissions. Approximately 1000 tonnes of mercury are released annually from ASM from at least 70 countries. An estimated $350 \mathrm{Mg} y r-1$ of this are directly emitted into the atmosphere while the remainder ( $650 \mathrm{Mg}$ yr-1) are released into the hydrosphere (rivers, lakes, soils, tailings). ${ }^{3}$ As well as being directly exposed, people can ingest mercury through foodstuffs, especially fish, since methylated mercury bioaccumulates. Mercury, and other chemical, pollution is cause for concern primarily because of the potentially-severe health impacts exposure to can produce, including effects on the nervous, digestive and immune systems, and on lungs, kidneys, skin and eyes (World Health Organization, 2017). These effects have been studied for several decades and are relatively well-described and well-quantified in the literature (see e.g. Malm et al. 1900 ; Palheta and Taylor, 1995; Limbong et al. 2003; Bose-O’Reilly et al 2003; Swain et al. 2007; Paruchuri et al. 2010; Gibb and O'Leary, 2014; Moody et al. 2020).

While there has been significant effort in quantifying mercury pollution, comparatively less attention has been paid to the social and policy implications of mercury use in ASM. There is a small but significant body of literature engaging with issues such as management techniques (e.g. Zolnikov and Ramirez Ortiz, 2018); capacity building (Mutemeri et al. 2016); education and awareness (Nkuba et al. 2018; Smith, 2019); the link between mercury and poverty (Hilson and Pardie, 2006); and policy initiatives, notably the Minimata Convention on Mercury (Clifford, 2014; Hilson et al. 2018). However, as Hilson et al. (2018: 123) noted recently, while the map of mercury pollution is 'nearly complete, knowledge of the livelihoods and community development dimensions remain poor'.

Although aspects of the environmental impact of ASM remain poorly quantified and knowledge is patchy in terms of spatial coverage, in general, the environmental impacts of the sector are well articulated. Given this wealth of knowledge, questions arise concerning why so little progress been made in addressing the environmental issues associated with ASM. The following section reviews the existing debates concerning the current state of ASM policy, before focussing on the SDGs and then their influence on the sector.

\subsection{Social and environmental trade-offs and corresponding policy debates: The large-scale bias, formalisation and knowledge}

Continued growth of ASM and mounting concern about the detrimental social and environmental aspects of its activities have triggered a period of reflection on the failure of policy and legislative instruments to address the sector's challenges. The idea of a 'largescale bias' and corresponding informality has emerged as key component within these debates (Hilson, 2013; Hilson, 2019). The explanation can be summarised as follows:

\footnotetext{
${ }^{2}$ Unlike riparian impacts, which can occur with any form of mining (e.g. sand and gravel mining, Yao et al. 2019; Narh, 2016), chemical pollution is predominantly associated with the use of mercury in artisanal and small-scale gold mining (although cyanide and arsenic are also significant chemical pollutants, see e.g. Knoblauch et al. 2020).

${ }^{3}$ A proportion of this will be volatized at some point.
} 
countries have prioritised incentivising investment in large-scale mining while the smallscale sector has been marginalised in policy. At the same time, ASM has seen burgeoning growth (driven by generally poor economic opportunities in rural areas). The resulting widespread informality has been inadequately addressed by legislative efforts that do not account for the realities of the sector. In particular, miners face a number of significant bureaucratic and financial challenges in obtaining concessions for ASM. Accordingly, formalisation processes (see below) have tended to favour relatively wealthy and wellconnected financiers and entrepreneurs at the expense of the majority of the work force (Verburgge, 2015). The effective criminalisation of the sector has impeded efforts to work with miners, for example in training them in better prospecting and efficient extraction methods.

Formalisation - efforts to integrate ASM into a legal framework governed by the state - has emerged as a core policy response to address the sector's challenges (Hilson and Maconachie, 2017; Hilson, 2019; Salo et al. 2016). However, the growing calls for formalisation have been met with a succession of nuanced responses. First, there are general concerns that formalisation of activities can reify existing inequalities (Putzel et al. 2015). Despite policy and legislative reform being rolled out with the intention of supporting poor resource users, formalisation can exacerbate the challenges they face by deepening the degree to which their activities are considered illegal (and therefore subject to forceful intervention - see Hilson, 2017) without developing appropriate avenues to formalise their activities. This has been the outcome of many existing reforms which place an extraordinary financial and bureaucratic burden on miners seeking concessions for their work (e.g. Hilson and Potter, 2003). Therefore, there is increasing recognition of the importance of taking account of the existing dynamics of the sector - specifically, understanding what Siegel and Veiga (2009) refer to as the 'extra-legal' economy of ASM is a key to designing appropriate policy interventions.

Second, there is growing appreciation of the context in which calls for ASM formalisation 'land'. In particular, the persistence of the large-scale bias is central to how future formalisation efforts will evolve. Hilson et al.'s (2019) recent work in Niger, for example, illustrates how governments might be content with continuing to neglect ASM, effectively leaving the sector's actors to their own devices, since it reduces the pressure on the government to distribute the benefits of large-scale mining among the citizenry. As Marshall and Veiga (2017) argue, formalisation is a necessary but insufficient component in addressing the challenges facing ASM. They argue formalisation per se will not necessarily deliver a more sustainable ASM sector and efforts must be accompanied with a sustained effort to further wider governance reforms (such as the formation of co-operatives) and deliver training and educational programmes for miners on more sustainable mining methods.

Together, these critiques of the formalisation agenda highlight the importance of appreciating both the local and wider (e.g. national) political economy and governance of the ASM sector. Such knowledge is critical to understanding who is mining where, how and why. While the general pattern of social and environmental issues related to ASM are well described, and in some cases depicted in considerable detail, understanding of the organisational dynamics is often, as Jonsson and Fold (2009) euphemistically put it, 
'modest'. Deficiencies in such understandings are related to both the wider neglect of the sector, typified by the large-scale bias explanation, and the informality that inhibits basic data collection efforts which, as has been long-argued, are central to designing effective policy interventions (Hilson and Maponga 2004; Hilson, 2005).

Having reviewed the primary environmental challenges with the ASM sector and situated them within the social and policy context, the paper turns now to examine the SDGs. It will explore how the SDG agenda will shape key issues in ASM, namely the large-scale bias, formalisation and knowledge of the sector.

\subsection{The Sustainable Development Goals: key features}

The SDGs followed on from the Millennium Development Goals. They have been praised for integrating social and economic development with environmental objectives, for broadening the process of goal setting and the scope of sustainable development to encompass all countries, and for the inclusion of private sector actors and civil society organisations. This expansion in scope and scale has not, however, been achieved through a process of navigating difficult trade-offs and prioritisations, but rather through a proliferation of goals, targets and indicators. While there were eight goals, 21 targets and 60 indicators associated with the MDGs, the SDGs consist of 17 goals, 169 targets and 232 indicators.

Despite the manifold and manifest connections between ASM and the SDGs, to understand the potential interactions, impacts and mutual prospects, it is pertinent to ask the question: 'what do the SDGs actually do?'. Despite lacking any clear theory of change (e.g. Seidman, 2017), proponents of the goals argue that they help to raise awareness of issues, help governments shape budgetary priorities, shape the flow of aid assistance and provide leverage for civil society organisations (CSOs) to lobby governments. However, how these avenues of change will actually operate to influence national policies will be shaped, in part, by the governance arrangements associated with the SDGs. Bierman et al. (2017) highlight several important governance features of the SDGs. First, each individual country is expected to take ownership and establish a national framework for the 17 goals, although there is no obligation to do so. This means, second, that states have considerable freedom to set their own priorities and implement goals as they choose. Third, the SDGs are characterised by weak institutional governance at the international level. As Abbott and Bernstein (2015) explain, the UN High-Level Political Forum is working with little authority and material resources, relying rather on governing by 'orchestration' (i.e., working indirectly through intermediary organizations, and using soft modes of influence to support and guide their actions).

The SDGs are effectively a non-binding set of global aspirations with weak institutional oversight arrangements and high levels of national discretion with respect to priorities. This has led to a divergence of views regarding their utility. On the one hand, some authors, disillusioned with top-down, prescriptive and internationally-led modes of development governance argue that the SDGs can be seen as deriving from a bottom-up, nonconfrontational, country-driven and stakeholder orientated process that might lead to 
previously unseen successes (e.g. Hajer et al. 2015; Stevens and Kanie, 2016). Others argue that while the SDG rhetoric is rich in the language of pluralism and participation, the muchlauded inclusion of the private sector will not necessarily lead to a departure from 'businessas-usual' (Scheyvens et al. 2016). There are others still who highlight the risk that indicators, which being necessarily reductive struggle to address the contested and complex components of 'sustainable development', will drive policy-development in ways which actually end up providing a veneer of neutrality and objectivity to policies that continue to exclude hitherto marginalised voices and hard to measure issues (Mair et al. 2017; FukudaParr and McNeill, 2019). As Cummings et al. (2017) note, while the discourse regarding the development of the SDGs is pluralist and participatory, the implementation of the goals is dominated by a techno-scientific-economic discourse. ${ }^{4}$ This privileges scientific and technical knowledge, and the economic instrumentalism of such forms of knowledge, at the expense of, inter alia, a diversity of forms of knowledge, different cultural and social values and an appreciation of the need for collective thinking. Furthermore, as Bierman et al. (2017) explain, optimism regarding the SDGs is based at least partly on a lack of alternative models; hope appears to be triumphing over expectation. They note that 'much will depend on the future policy development around these goals over the next years, from the evolution of the global institutional arrangements to the ambition of the eventual national and sub-national implementation process to attain the goals' (p. 27).

Against this background, it is important to keep in mind the state and its efforts to govern, but also how parties 'beyond the state' such as multi-lateral donors, corporations, consultancies, non-governmental organisations, customary authorities, academics and activists, engage and shape governance arrangements. As Li (2005), engaging with Scott (1998) and Ferguson (1994), argues, questions concerning why improvement schemes so often fail can usefully be re-framed to focus rather on what schemes do and how they generate messy, contradictory and refractory effects. In this spirit, the paper now turns to unpacking how the SDGs might shape the ASM sector by reflecting on the three key threads identified previously, the state of knowledge regarding the sector, debates on formalisation and large-scale bias in mining policy.

\section{How do the SDGs influence the focus of mining policy: who counts?}

Any efforts to harness the SDGs agenda to mitigate environmental and social challenges within ASM requires reversing the persistent marginalisation of the sector within policymaking circles. To date, the signs are not encouraging. In 2016, the United Nations Development Programme (UNDP), together with the World Economic Forum and the Columbia Center on Sustainable Investments and the Sustainable Development Solutions Network, published a report entitled: 'Mapping Mining to the SDGs: An Atlas' (UNDP, 2016). The report references ASM only to note that the Atlas focuses on large-scale mining, and that the 'scale of ASM warrants a separate guide and review to map the opportunities on

\footnotetext{
${ }^{4}$ This reflects a broader trend in the allocation of environmental and sustainability research funding as is clearly illustrated in the context of climate change where a recent analysis by Overland and Sovacool (2020) show that between ' 1990 and 2018 , the natural and technical sciences received $770 \%$ more funding than the social sciences'.
} 
how ASM can contribute to the SDGs' (UNDP, 2016:16). However, an equivalently wellresourced report for ASM is yet to materialise. ${ }^{5}$

As noted above, the SDGs are characterised by an absence of any top-down priority setting mechanisms. States have the freedom to pursue (or ignore) the goals however they want. While the long and well-documented history of failure of coercive, top-down development planning (Scott, 1998; Easterly, 2006) cautions against unqualified critique of the existing SDG process, it is difficult to imagine how ASM, and other informal, marginalised, sectors of the economy will suddenly shoot up countries' priority lists. The constellations of actors beyond the state, typified by the contributors to the Mining and the SDG Atlas, suggest that neither the SDGs themselves nor the wider political economy provides any basis for optimism.

Large-scale mining continues to be at the heart of development strategies. Echoing earlier ideas of trickle-down benefits, the World Bank and other international donors have championed investment, from multi-national companies and financiers, in large-scale mining as a potential foundation for building 'growth poles' (Speakman and Koivisto, 2013). These multi-sectoral investments projects aim to capitalize on and augment opportunities that already exist in an economy to generate spillover benefits in the wider economy. The emergence of the 'growth pole' rhetoric, has, as Lesutis (2019) describes in the Mozambican context, coincided with shifts in the broader dynamics of the national economy that 'since the turn of the century has come to be focused on large-scale natural resource extractionoriented projects and infrastructures, tightly aligned with interests of political and economic elites in the capital...' (p. 118). However, much of the evaluative work by scholars on such investments concludes that rather than delivering wider economic benefits or providing a springboard for local economic development, they often create development 'enclaves' which exacerbate inequalities (Ferguson, 2006; Sidaway, 2007; Côte and Korf, 2018) ${ }^{6}$.

For decision-makers in resource-rich countries, there are minimal incentives to prioritise the development of ASM. And, within the SDGs themselves, there is little leverage available to change this. The inclusion of SDG 16 (Peace, Justice and Strong Institutions) and 17 (Partnerships for the Goals) demonstrate a recognition of the importance of governance issues and collaborative governance arrangements in addressing the SDGs. However, examining the targets associated with these goals reveals that the underlying logic of the goals is not conducive to addressing marginalised sectors. While, SDG 16 leaves a lot of scope for states to pursue different avenues for institutional reform, the goal in general emphasises state power and statutory legislation (McDermott et al. 2019). SDG 17 highlights the need to 'Respect each country's policy space and leadership to establish and implement policies for poverty eradication and sustainable development' (target 17.15). The direction of this leadership, it is envisaged, will be guided by multi-stakeholder partnerships that mobilize and share knowledge, expertise, technology and financial resources (target 17.16), and be delivered through public, public-private and civil society partnerships (target 17.17). The question this raises is: 'who or what organisations are best placed to engage with multistakeholder partnerships and share knowledge, expertise, technology and finance?'

\footnotetext{
${ }^{5}$ Although ASM did receive some attention in the recent UNEP-IRP report Mineral Resource Governance Report in the $21^{\text {st }}$ Century (IRP, 2020).

${ }^{6}$ For a counter to this argument, see, for example, Bloch and Owusu (2012).
} 
Evidently, large-scale mining (and large-scale, formalised industries in general), with their concentration of wealth and experience of engaging with nation states are more likely to be engaged than the diffuse and relatively poor actors within the ASM sector.

Despite the obvious scope for synergies between ASM and the SDGs, the SDGs appear to largely entrench states' power and priorities, meaning the neglect and marginalisation of ASM seems likely to continue. There is little reason to believe that ASM will suddenly shoot up the priority list without a concerted effort to thrust the sector onto the development agenda. Simply hoping that the ostensibly iterative and bottom-up processes embedded in the SDG will move ASM up the agenda is misguided. The SDGs do, however, potentially provide leverage for CSOs and other actors to lobby states. To what extent this might occur in the ASM sector is unclear. However, such efforts are likely to be orientated around formalisation and so the paper now turns to examine in more detail how the SDGs might influence the formalisation agenda.

\section{How will the SDGs influence formalisation of ASM?}

Formalisation of ASM has garnered considerable interest in recent years. To date, formalisation efforts have primarily been orientated around the provision of mining titles for ASM concessions (Hilson et al. 2019). There are several logics employed to justify this strategy. With respect to addressing environmental issues it is argued that formalising the sector would enable some degree of centralised control over where and how ASM happens (Hook, 2019). Other relevant arguments contend that formalisation would support ASM livelihoods by securing miners' right to work, facilitate the provision of support to miners (e.g. financial and technical) and protect miners from the risks associated with operating informally, such as the use of law enforcement to stop mining activities.

A key question is how SDGs will shape efforts to formalise the sector. SDG 16 provides the basis for engaging with statutory legislation, with target 16.3 being to: 'Promote the rule of law at the national and international levels and ensure equal access to justice for all'. While this certainly gives scope for interested parties to engage with issues associated with formalising ASM the specific indicators are not directly relevant. These relate to the proportion of victims of violence reporting their victimisation (16.3.1) and proportion of unsentenced detainees as a proportion of total prison population (16.3.2). It seems unlikely then that the SDGs will be particularly influential with respect to the central policy issue in ASM. Furthermore, the growing literature on formalisation ASM problematises a simple 'legalist' solution - the granting formal titles to small-scale miners - to the formalisation question. There are several important issues to review because the state-centric view of governance embedded within the SDGs appear to support such a legalist approach to informal activities.

First, as Verbrugge (2015) clearly elucidates in the case of the Philippines, existing efforts to formalise the sector have failed to account for the heterogeneity of actors involved in the sector and therefore largely benefitted the ASM 'entrepreneurial' elites at the expense of the poverty-driven primary workforce. Although this might deliver environmental control to 
central state authorities and help address environmental SDGs, this comes at a cost with respect to supporting goals associated with poverty (SDG 1) and inequality (SDG 10).

Second, Hook (2019a, b) shows that in Guyana where there is a relatively mature and wellfunctioning formal ASM sector, formalisation can fail to contain or control the environmental impacts of mining. Miners who secure formal mining titles continue to face various challenge that lead to institutional 'overspill' with associated environmental and social implications. These include: 1) forms of techno-financial exclusion where environmental requirements (such as using a spiral concentrator or constructing a tailings dam) or the geological character of mineral deposits (e.g. depth) mean that even formal miners are faced with the choice between leaving the sector or operating illegally (either by not aligning their activities with regulations or by spilling over into areas outside of the formal concession where they can mine using technology available to them); 2) sociopolitical challenges associated with landlord-tenant relations that mean miners themselves might be insecure despite operating at a site on a formal concession and 3) difficulty accessing state support where the resources available to support and regulate the sector do not match the scale (e.g. 90 officers, none of whom are permanently based 'in the field' cover 3000 licensed operations over 83,000 square miles) (see also Marshall and Veiga, 2017). These analyses cast doubt on claims that formalisation, the granting of formal licences will, per se, deliver on either environmental or social goals.

Finally, Hilson et al. (2019) draws on empirical evidence from Ghana and Niger to question, on a number of grounds, whether simply granting miners legitimate licences could enable them to transition away from the dynamics of the informal economy that is now so deeply entrenched. These include, for example, miners' negotiations with, and payments to, customary authorities and land owners that operate largely independently from (beyond) state authorities and who largely dictate questions of who gets to mine, and where, regardless of the status of miners' formal mining title.

Evidently, while formalisation is likely to remain central to ASM policy over the time span of the SDGs, the existing approaches seem largely disconnected from the realities of the sector and are therefore unlikely to generate any synergies with the overarching normative goals embedded in the SDGs. Furthermore, the state-centric nature of the SDGs and the emphasis on the 'rule of law' might entrench legalistic framings leading policy initiatives to overlook the dynamics of ASM governance. This will likely reduce the impact of reforms aimed at addressing environmental impacts of the sector and could deliver detrimental impacts on ASM communities. Overhauling existing formalisation frameworks is critical to tackling the current trajectory of ASM policy and consequent impacts (Hilson et al. 2017). Doing so requires investing in developing a much more robust understanding of the sector, challenging assumptions about the homogeneity of the ASM sector and engaging with the 'complex organizational arrangements in a sector composed of an entire range of stakeholders' (Verbrugge and Besmanos, 2016).

\section{What kind of knowledge is needed and will the SDGs help deliver it?}


Environmental issues are often central to debates on ASM, and frequently invoked in antiASM discourses. Reflecting the sector as a whole, precise and spatially specific knowledge of the environmental impacts of ASM is often missing. However, this does not mean that measuring environmental impacts should be the priority for researchers and organisations seeking to address these impacts. The environmental impacts of ASM are largely a symptom or outcome of a particular set of governance arrangements that shape where and how ASM activities happen. Higher resolution analyses of deforestation and degradation, or more finely tuned estimates of mercury exposure might help put issues 'on the radar', but ultimately more of these analyses simply serve to ramp up ambition and reinforce aspirational goal setting modes of governance but do little to actually help guide effective policy development. There is a considerable risk that ASM research follows the trend set in research on deforestation which, through a narrowing of scope from sustainability to carbon, has mostly served to simply increase our ability to 'watch forests change' (McDermott, 2014:17). Remote sensing and modelling studies that focus on quantifying, for example, the impact of ASM on forests or measuring exposure to mercury, are an important part of developing coherent strategies to tackle environmental and social challenges, but they are potentially counter-productive if they serve to divert resources or attention away from core governance issues.

With respect to the environmental impacts of ASM, understanding the patterns of authority, legitimacy and power that actually dictate where mining happens and how is critical. Understanding who, both in terms of individuals and collectives, is dictating ASM decision-making, and why, is central to any effort to developing future policy initiatives, including overhauling formalisation frameworks. As Hilson (2019) notes, this includes cultural and attitudinal perspectives towards the sector. It is also essential that efforts to understand the sector's governance encompasses more than the state and formal regulatory bodies involved. It must also include the miners themselves, customary authorities, private corporations including mining companies, donors and nongovernmental organisations and their interactions. Integrating this knowledge with other disciplines is also critical. Adequate geological maps that might facilitate, for example, the sharing of concessions between large-scale mining and ASM (who usually target different kinds of mineral deposits) are essential foundational sources of knowledge, as are the political dynamics which impinge on such sharing agreements (e.g. Hilson et al. 2020; Aubynn 2009).

There are evidently a number of ways to approach these areas of research. Drawing on the rich diversity of methods, concepts and approaches used in the social sciences and humanities is needed. The intention here is not to be exhaustive or prescriptive about methods or particular research questions, but rather to emphasise the paucity of relevant knowledge required to tackle the environmental and social challenges associated with ASM. And to question whether the SDGs help deliver such knowledge. The SDGs are, as Cummings et al. (2017) demonstrate, dominated by a 'techno-scientific-economic' knowledge discourse, particularly in the context of their delivery. As Fukuda-Parr and McNeill (2019) note, while negotiations concerning indicators related to the SDGs are portrayed as a technical matter they are in fact highly political but these dynamics remain 'obscured behind the veil of an objective and technical choice'. The influence of states and 
corporations extends well beyond the final text of the SDGs and serves to exclude a range of alternative knowledge discourses and maintain the status quo in their design and delivery.

The same constellation of actors that will facilitate the entrenchment of the large-scale bias in mining policy (see section 4) could further entrench their power by circumscribing the kinds of knowledge generated and included in deliberations on how to pursue, and measure progress towards, the SDGs. For example, the lack of basic census data on ASM communities has been flagged for more than 15 years (Hilson and Maponga, 2004); yet, progress in understanding the sector has progressed at an extremely slow pace. The political economy of knowledge regarding ASM is among the key issues that requires transforming in the coming decade if synergies between the SDGs and ASM are to emerge. Yet, as the Mining and the SDG Atlas typifies, the prospects for the required sustained and detailed data collection and analysis are poor.

\section{Concluding remarks}

On the whole, ASM is a sector characterised by widespread poverty and environmental degradation. Accordingly, it could potentially contribute to or undermine the achievement of the SDGs. Existing literature on ASM, reviewed here, indicates that addressing the social and environmental issues associated with ASM depend critically on three related issues. First, addressing the ongoing marginalisation of the sector in policy. Second, developing strategies for formalisation that minimises the risks of exacerbating existing inequality and inefficacy by accounting for the heterogeneity of the actors involved. And third, developing a knowledge base that illuminates the dynamics of the sector which predominantly operates informally. The longer-term effects of the aspirational goal-setting focus of the SDGs, underpinned by a constellation of state and corporate interests, remain to be seen. But it appears the immediate effect has been to entrench the large-scale bias in mining policy, maintain framings of the formalisation agenda that are disconnected from the realities of the sector and marginalise efforts to generate the grounded knowledge which will be integral to any efforts to deliver effective policy. In essence, the prospects for the SDGs contributing positively to efforts to address environmental and social issues in ASM are poor. Similar arguments apply across a range of important natural resource-based sectors, such as forestry and agriculture (e.g. Putzel et al. 2015; Hirons, 2018), where informality and poverty are widespread.

However, to simply conclude the SDGs will fail would be simplistic. Rather, the SDGs will deliver a range of messy, contradictory and refractory effects (after Li, 2005). A diverse group of actors and interests will continue to engage a number of strategies to try and leverage the SDGs in support of particular goals. As the SDG process evolves, it is essential that scholars and actors committed to navigating the complex terrain associated with environmental and social concerns are not distracted by simply measuring whether or not particular goals are being met, but focus primarily on what the implementation of aspirational goal-setting agendas actually deliver with respect to the lives of their intended beneficiaries and the environments they inhabit in particular contexts. Such an understanding can inform strategies to resist the more pernicious effects of ostensibly unobjectionable global agendas. 


\section{Acknowledgements}

I gratefully acknowledge two anonymous reviewers for providing constructive feedback on previous drafts. I would also like to thank the Ecosystems Governance group at the Environmental Change Institute (ECI) at the University of Oxford, especially Connie McDermott, for their support. 


\section{References}

Abbott, K. W., \& Bernstein, S. (2015). The high-level political forum on sustainable development: Orchestration by default and design. Global Policy, 6(3), 222-233.

Asner, G. P., Llactayo, W., Tupayachi, R., \& Luna, E. R. (2013). Elevated rates of gold mining in the Amazon revealed through high-resolution monitoring. Proceedings of the National Academy of Sciences, 110(46), 18454-18459.

Asner, G. P., \& Tupayachi, R. (2017). Accelerated losses of protected forests from gold mining in the Peruvian Amazon. Environmental Research Letters, 12(9), 094004.

Aubynn, A. (2009). Sustainable solution or a marriage of inconvenience? The coexistence of large-scale mining and artisanal and small-scale mining on the Abosso Goldfields concession in Western Ghana. Resources Policy, 34(1-2), 64-70.

Banchirigah, S. M., \& Hilson, G. (2010). De-agrarianization, re-agrarianization and local economic development: Re-orientating livelihoods in African artisanal mining communities. Policy Sciences, 43(2), 157-180.

Bansah, K. J. (2019). From diurnal to nocturnal: Surviving in a chaotic artisanal and smallscale mining sector. Resources Policy, 64, 101475.

Bansah, K. J., Dumakor-Dupey, N. K., Kansake, B. A., Assan, E., \& Bekui, P. (2018).

Socioeconomic and environmental assessment of informal artisanal and small-scale mining in Ghana. Journal of Cleaner Production, 202, 465-475.

Biermann, F., Kanie, N., \& Kim, R. E. (2017). Global governance by goal-setting: the novel approach of the UN Sustainable Development Goals. Current Opinion in Environmental Sustainability, 26, 26-31.

Bloch, R., \& Owusu, G. (2012). Linkages in Ghana's gold mining industry: Challenging the enclave thesis. Resources Policy, 37(4), 434-442.

Bose-O'Reilly, S., Drasch, G., Beinhoff, C., Tesha, A., Drasch, K., Roider, G., ... \& Siebert, U. (2010). Health assessment of artisanal gold miners in Tanzania. Science of the total Environment, 408(4), 796-805.

Bryceson, D. F., \& Geenen, S. (2016). Artisanal frontier mining of gold in Africa: Labour transformation in Tanzania and the Democratic Republic of Congo. African Affairs, 115(459), 296-317.

Clifford, M. J. (2014). Future strategies for tackling mercury pollution in the artisanal gold mining sector: Making the Minamata Convention work. Futures, 62, 106-112. 
Côte, M., \& Korf, B. (2018). Making concessions: Extractive enclaves, entangled capitalism and regulative pluralism at the gold mining frontier in Burkina Faso. World Development, 101, 466-476.

Cummings, S., Regeer, B., de Haan, L., Zweekhorst, M., \& Bunders, J. (2018). Critical discourse analysis of perspectives on knowledge and the knowledge society within the Sustainable Development Goals. Development Policy Review, 36(6), 727-742.

Dondeyne, S., Ndunguru, E., Rafael, P., \& Bannerman, J. (2009). Artisanal mining in central Mozambique: Policy and environmental issues of concern. Resources Policy, 34(1-2), 45-50.

Easterly, W. (2006). The white man's burden: why the West's efforts to aid the rest have done so much ill and so little good. New York: Penguin Press.

Ferguson, J. (2006). Global shadows. Africa in the neoliberal world order Duke University Press, Durham and London.

Ferring, D., Hausermann, H., \& Effah, E. (2016). Site specific: Heterogeneity of smallscale gold mining in Ghana. The Extractive Industries and Society, 3(1), 171-184.

Gandiwa, E., \& Gandiwa, P. (2012). Biodiversity conservation versus artisanal gold mining: a case study of Chimanimani National Park, Zimbabwe. Journal of Sustainable Development in Africa, 14(6), 29-37.

Ghose, M. K. (2003). Promoting cleaner production in the Indian small-scale mining industry. Journal of Cleaner Production, 11(2), 167-174.

Gibb, H., \& O'Leary, K. G. (2014). Mercury exposure and health impacts among individuals in the artisanal and small-scale gold mining community: a comprehensive review. Environmental health perspectives, 122(7), 667-672.

Griggs, D., Stafford-Smith, M., Gaffney, O., Rockström, J., Öhman, M. C., Shyamsundar, P., ... \& Noble, I. (2013). Policy: Sustainable development goals for people and planet. Nature, 495(7441), 305.

Fukuda-Parr, S., \& McNeill, D. (2019). Knowledge and Politics in Setting and Measuring the SDG s: Introduction to Special Issue. Global Policy, 10, 5-15.

Hák, T., Janoušková, S., \& Moldan, B. (2016). Sustainable Development Goals: A need for relevant indicators. Ecological Indicators, 60, 565-573.

Hajer, M., Nilsson, M., Raworth, K., Bakker, P., Berkhout, F., De Boer, Y., ... \& Kok, M. (2015). Beyond cockpit-ism: Four insights to enhance the transformative potential of the sustainable development goals. Sustainability, 7(2), 1651-1660. 
Hentschel, T., Hruschka, F., \& Priester, M. (2002). Global report on artisanal and smallscale mining Mining, Minerals and Sustainable Development: International Institute for Environment and Development.

Hilson, G. (2002). Land use competition between small-and large-scale miners: a case study of Ghana. Land Use Policy, 19(2), 149-156.

Hilson, G. (2005). Strengthening artisanal mining research and policy through baseline census activities. Natural Resources Forum 29 (2), 144-153

Hilson, G. (2012). Poverty traps in small-scale mining communities: the case of subSaharan Africa. Canadian Journal of Development Studies/Revue canadienne d'études du développement, 33(2), 180-197.

Hilson, G. (2013). " Creating" Rural Informality: The Case of Artisanal Gold Mining in SubSaharan Africa. SAIS Review of International Affairs, 33(1), 51-64.

Hilson, G. (2016). Farming, small-scale mining and rural livelihoods in Sub-Saharan Africa: A critical overview. The Extractive Industries and Society, 3(2), 547-563.

Hilson, G. (2017). Shootings and burning excavators: Some rapid reflections on the Government of Ghana's handling of the informal Galamsey mining 'menace'. Resources Policy, 54, 109-116.

Hilson, G. (2019). Why is there a large-scale mining 'bias' in sub-Saharan Africa? Land use policy, 81, 852-861.

Hilson, G., Sauerwein, T., \& Owen, J. (2020). Large and artisanal scale mine development: The case for autonomous co-existence. World Development, 130, 104919.

Hilson, G., Goumandakoye, H., \& Diallo, P. (2019). Formalizing artisanal mining 'spaces' in rural sub-Saharan Africa: The case of Niger. Land use policy, 80, 259-268.

Hilson, G., Hilson, A., Maconachie, R., McQuilken, J., \& Goumandakoye, H. (2017). Artisanal and small-scale mining (ASM) in sub-Saharan Africa: Re-conceptualizing formalization and 'illegal' activity. Geoforum, 83, 80-90.

Hilson, G., \& Maconachie, R. (2017). Formalising artisanal and small-scale mining: insights, contestations and clarifications. Area, 49 (4), 443-451.

Hilson, G., \& Maconachie, R. (2020). Artisanal and small-scale mining and the Sustainable Development Goals: Opportunities and new directions for sub-Saharan Africa. Geoforum, 111, 125-141.

Hilson, G., \& Maponga, O. (2004). How has a shortage of census and geological information impeded the regularization of artisanal and small-scale mining?. Natural Resources Forum, 28 (1), 22-33. 
Hilson, Gavin, and James McQuilken. (2014). Four decades of support for artisanal and small-scale mining in sub-Saharan Africa: a critical review." The Extractive Industries and Society, 1, 104-118.

Hilson, G., \& Pardie, S. (2006). Mercury: an agent of poverty in Ghana's small-scale goldmining sector?. Resources Policy, 31(2), 106-116.

Hilson, G., \& Potter, C. (2003). Why is illegal gold mining activity so ubiquitous in rural Ghana?. African Development Review, 15(2-3), 237-270.

Hilson, G., Zolnikov, T. R., Ortiz, D. R., \& Kumah, C. (2018). Formalizing artisanal gold mining under the Minamata convention: Previewing the challenge in Sub-Saharan Africa. Environmental Science \& Policy, 85, 123-131.

Hirons, M. (2011). Managing artisanal and small-scale mining in forest areas: perspectives from a poststructural political ecology. The Geographical Journal, 177(4), 347-356.

Hirons, M. (2011). Locking-In Carbon, Locking-Out Livelihoods? Artisanal Mining and REDD+ in Sub-Saharan Africa. Journal of International Development, 23(8), 1140-1150.

Hirons, M. (2013). Mining in Ghana's forests: cross-sectoral linkages and the prospects for REDD. International Development Planning Review, 35(3), 283-302.

Hirons, M. (2015). Trees for development? Articulating the ambiguities of power, authority and legitimacy in governing Ghana's mineral rich forests. The Extractive Industries and Society, 2(3), 491-499.

Hook, A. (2019a). Over-spilling institutions: The political ecology of 'greening'the smallscale gold mining sector in Guyana. Land use policy, 85, 438-453.

Hook, A. (2019b). The multidimensionality of exclusion in the small-scale gold mining sector in Guyana: Institutional reform, landlordism, and mineral uncertainty. World Development, 123, 104607.

Hosonuma, N., Herold, M., De Sy, V., De Fries, R. S., Brockhaus, M., Verchot, L., ... \& Romijn, E. (2012). An assessment of deforestation and forest degradation drivers in developing countries. Environmental Research Letters, 7(4), 044009.

IGF (Intergovernmental Forum on Mining, Minerals, Metals and Sustainable Development). (2017). Global Trends in Artisanal and Small-Scale Mining (ASM): A review of key numbers and issues. Winnipeg: IISD.

IRP (International Resource Panel), (2020). Mineral Resource Governance in the 21st Century: Gearing extractive industries towards sustainable development. Ayuk, E. T., Pedro, A. M., Ekins, P., Gatune, J., Milligan, B., Oberle B., Christmann, P., Ali, S., Kumar, S. 
V, Bringezu, S., Acquatella, J., Bernaudat, L., Bodouroglou, C., Brooks, S., Buergi Bonanomi, E., Clement, J., Collins, N., Davis, K., Davy, A., Dawkins, K., Dom, A., Eslamishoar, F., Franks, D., Hamor, T., Jensen, D., Lahiri-Dutt, K., Mancini, L., Nuss, P., Petersen, I., Sanders, A. R. D. A Report by the International Resource Panel. United Nations Environment Programme, Nairobi, Kenya.

Kim, R. E. (2016). The nexus between international law and the sustainable development goals. Review of European, Comparative \& International Environmental Law, 25(1), 1526.

Knoblauch, A. M., Farnham, A., Ouoba, J., Zanetti, J., Müller, S., Jean-Richard, V., ... \& Winkler, M. S. (2020). Potential health effects of cyanide use in artisanal and small-scale gold mining in Burkina Faso. Journal of Cleaner Production, 252, 119689.

Kumi, E., Arhin, A. A., \& Yeboah, T. (2014). Can post-2015 sustainable development goals survive neoliberalism? A critical examination of the sustainable developmentneoliberalism nexus in developing countries. Environment, development and sustainability, 16(3), 539-554.

Lesutis, G. (2019). Spaces of extraction and suffering: Neoliberal enclave and dispossession in Tete, Mozambique. Geoforum, 102, 116-125.

Li, T. M. (2005). Beyond "the state" and failed schemes. American anthropologist, 107(3), 383-394.

Limbong, D., Kumampung, J., Rimper, J., Arai, T., \& Miyazaki, N. (2003). Emissions and environmental implications of mercury from artisanal gold mining in north Sulawesi, Indonesia. Science of the Total Environment, 302(1-3), 227-236.

Liverman, D. M. (2018). Geographic perspectives on development goals: Constructive engagements and critical perspectives on the MDGs and the SDGs. Dialogues in Human Geography, 8(2), 168-185.

Maconachie, R. (2011). Re-agrarianising livelihoods in post-conflict Sierra Leone? Mineral wealth and rural change in artisanal and small-scale mining communities. Journal of International Development, 23(8), 1054-1067.

Malm, O., Pfeiffer, W. C., Souza, C. M., \& Reuther, R. (1990). Mercury pollution due to gold mining in the Madeira River basin, Brazil. ambio, 19(1), 11-15.

Marshall, B. G., \& Veiga, M. M. (2017). Formalization of artisanal miners: stop the train, we need to get off!. The Extractive Industries and Society, 4(2), 300-303.

Masocha, M., Dube, T., Mambwe, M., \& Mushore, T. D. (2019). Predicting pollutant concentrations in rivers exposed to alluvial gold mining in Mazowe Catchment, Zimbabwe. Physics and Chemistry of the Earth, Parts A/B/C, 112, 210-215. 
McDermott, C. L. (2014). REDDuced: From sustainability to legality to units of carbonThe search for common interests in international forest governance. Environmental Science \& Policy, 35, 12-19.

McDermott, C. L., Acheampong, E., Arora-Jonsson, S., Asare, R. A., De Jong, W., Hirons, M., ... \& Setyowati, A. (2019). SDG 16: Peace, justice and strong institutions: a political ecology perspective.

Moody, K. H., Hasan, K. M., Aljic, S., Blakeman, V. M., Hicks, L. P., Loving, D. C., ... \& Kiefer, A. M. (2020). Mercury emissions from Peruvian gold shops: Potential ramifications for Minamata compliance in artisanal and small-scale gold mining communities. Environmental Research, 182, 109042.

Mutemeri, N., Walker, J. Z., Coulson, N., \& Watson, I. (2016). Capacity building for selfregulation of the Artisanal and Small-Scale Mining (ASM) sector: A policy paradigm shift aligned with development outcomes and a pro-poor approach. The Extractive Industries and Society, 3(3), 653-658.

Narh, P. (2016). Sand winning in Dormaa as an interlocking of livelihood strategies with environmental governance regimes. Environment, development and sustainability, 18(2), 467-480.

Nkuba, B., Bervoets, L., \& Geenen, S. (2019). Invisible and ignored? Local perspectives on mercury in Congolese gold mining. Journal of cleaner production, 221, 795-804.

Palheta, D., \& Taylor, A. (1995). Mercury in environmental and biological samples from a gold mining area in the Amazon region of Brazil. Science of the Total Environment, 168(1), 63-69.

Paruchuri, Y., Siuniak, A., Johnson, N., Levin, E., Mitchell, K., Goodrich, J. M., ... \& Basu, N. (2010). Occupational and environmental mercury exposure among small-scale gold miners in the Talensi-Nabdam District of Ghana's Upper East region. Science of the total environment, 408(24), 6079-6085.

Potapov, P. V., Dempewolf, J., Talero, Y., Hansen, M. C., Stehman, S. V., Vargas, C., ... \& Giudice, R. (2014). National satellite-based humid tropical forest change assessment in Peru in support of REDD+ implementation. Environmental Research Letters, 9(12), 124012.

Putzel, L., Kelly, A. B., Cerutti, P. O., \& Artati, Y. (2015). Formalization as development in land and natural resource policy. Society \& Natural Resources, 28(5), 453-472.

Salo, M., Hiedanpää, J., Karlsson, T., Ávila, L. C., Kotilainen, J., Jounela, P., \& García, R. R. (2016). Local perspectives on the formalization of artisanal and small-scale mining in the Madre de Dios gold fields, Peru. The Extractive Industries and Society, 3(4), 1058-1066. 
Scheyvens, R., Banks, G., \& Hughes, E. (2016). The private sector and the SDGs: The need to move beyond 'business as usual'. Sustainable Development, 24(6), 371-382.

Scullion, J. J., Vogt, K. A., Sienkiewicz, A., Gmur, S. J., \& Trujillo, C. (2014). Assessing the influence of land-cover change and conflicting land-use authorizations on ecosystem conversion on the forest frontier of Madre de Dios, Peru. Biological Conservation, 171, 247-258.

Seidman, G. (2017). Does SDG 3 have an adequate theory of change for improving health systems performance?. Journal of global health, 7(1).

Sidaway, J. D. (2007). Enclave space: a new metageography of development?. Area, 39(3), 331-339.

Siegel, Shefa, and Marcello M. Veiga. "Artisanal and small-scale mining as an extralegal economy: De Soto and the redefinition of "formalization". " Resources policy 34.1-2 (2009): 51-56.

Smith, N. M. (2019). "Our gold is dirty, but we want to improve": Challenges to addressing mercury use in artisanal and small-scale gold mining in Peru. Journal of cleaner production, 222, 646-654.

Speakman and Kovisto:

http://www3.weforum.org/docs/ACR/2013/ACR Chapter2.3 2013.pdf

Stafford-Smith, M., Griggs, D., Gaffney, O., Ullah, F., Reyers, B., Kanie, N., ... \& O'Connell, D. (2017). Integration: the key to implementing the Sustainable Development Goals. Sustainability Science, 12(6), 911-919.

Stevens, C., \& Kanie, N. (2016). The transformative potential of the sustainable development goals (SDGs). International Environmental Agreements: Politics, Law and Economics, 16(3) 393-396.

Swain, E. B., Jakus, P. M., Rice, G., Lupi, F., Maxson, P. A., Pacyna, J. M., ... \& Veiga, M. M. (2007). Socioeconomic consequences of mercury use and pollution. Ambio, 45-61.

Swenson, J. J., Carter, C. E., Domec, J. C., \& Delgado, C. I. (2011). Gold mining in the Peruvian Amazon: global prices, deforestation, and mercury imports. PloS one, 6(4).

Tarras-Wahlberg, N. H., Flachier, A., Fredriksson, G., Lane, S., Lundberg, B., \& Sangfors, O. (2000). Environmental impact of small-scale and artisanal gold mining in southern Ecuador. AMBIO: A Journal of the Human Environment, 29(8), 484-491

Telmer, K. H., \& Veiga, M. M. (2009). World emissions of mercury from artisanal and small scale gold mining. In Mercury fate and transport in the global atmosphere (pp. 131-172). Springer, Boston, MA. 
United Nations. (2020). Sustainable Development Goals. Available online:

https://sustainabledevelopment.un.org/?menu=1300 [Accessed 30.1.2020]

Verbrugge, B. (2015). The economic logic of persistent informality: artisanal and smallscale mining in the southern Philippines. Development and Change, 46(5), 1023-1046.

Verbrugge, B., Besmanos, B., 2016. Formalizing artisanal and small-scale mining: whither the workforce? Resources Policy 47(1), 134-141.

World Health Organisation (WHO). (2017) Mercury and Health. Available online: https://www.who.int/news-room/fact-sheets/detail/mercury-and-health [Accessed 30.1.2020].

Yakovleva, N. (2007). Perspectives on female participation in artisanal and small-scale mining: A case study of Birim North District of Ghana. Resources Policy, 32(1-2), 29-41.

Yao, J., Zhang, D., Li, Y., Zhang, Q., \& Gao, J. (2019). Quantifying the hydrodynamic impacts of cumulative sand mining on a large river-connected floodplain lake: Poyang Lake. Journal of Hydrology, 579, 124156.

Zolnikov, T. R., \& Ortiz, D. R. (2018). A systematic review on the management and treatment of mercury in artisanal gold mining. Science of the Total Environment, 633, 816-824.

Zvarivadza, T. (2018). Artisanal and small-scale mining as a challenge and possible contributor to sustainable development. Resources Policy, 56, 49-58. 